\title{
MANUSCRIPT TITLE- CEPHALOMETRIC VERTICAL CHARACTERISTIC OF SKELETAL CLASS II MALOCCLUSION IN SOUTH RAJASTHAN POPULATION
}

\author{
1.Dr.RONIK NARAYANI-PH.NO: 8112205316 \\ roniknaryani10@gmail.com \\ 2.Dr NEERAL BARTHUNIA -PH .NO.-9829200271 \\ orthoneeral5@yahoo.co.in \\ 3.Dr SANDEEP SINGH BHATIA - PH.NO.- 8824003366 \\ sandeep1585@gmail.com \\ 4.Dr.RISHI MANGAL -PH.NO :9929825887 \\ rishimangalpdc@gmail.com \\ 5.Dr.HAJIRA BHANU.S -PH.NO: 9629775839 \\ haji.bhanu.com@gmail.com \\ 6.Dr.RUGHANI DARSH ANIL-PH NO:7760718808 \\ darsh7.dr@gmail.com
}

Corresponding Author - .Dr.RONIK NARAYANI-PH.NO: 8112205316

Email id-roniknaryani10@gmail.com

${ }^{1}$ Post graduate student, Department of Orthodontics and Dentofacial Orthopaedics,

Daswani dental college and Research Center.

${ }^{2}$ Professor and Head of the Department of Orthodontics and Dentofacial

Orthopaedics, Daswani dental college and Research Center.

${ }^{3}$ Reader, Department of Orthodontics and Dentofacial Orthopaedics, Daswani dental college and Research Center.

${ }^{4}$ Reader, Department of Orthodontics and Dentofacial Orthopaedics, Daswani dental college and Research Center.

${ }^{5}$ Post graduate student, Department of Orthodontics and Dentofacial

Orthopaedics,Daswani dental college and Research Center.

${ }^{6}$ Post graduate student, Department of Orthodontics and Dentofacial Orthopaedics, Daswani dental college and Research Center.

\section{ABSTRACT}

Introduction: To describe the cephalometric vertical characteristic of skeletal Class II malocclusion in South Rajasthan population at Daswani Dental College and Research Center. Methods: A total of 100 lateral cephalograms of pre-orthodontic patients with skeletal Class II malocclusion were obtained from Daswani Dental College and Research Center. The lateral cephalograms were taken using digital cephalometric machine and were analyzed by manual 
tracing with experienced post graduates to determine the ANB, mandibular length, facial axis, $Y$-axis, sella to nasion-mandibular plane (SN-MP), lower anterior facial height (LAFH), FMA, gonial angle, saddle angle and articulare angle Correlation between mandibular length and other variables was analyzed using Pearson correlation test with $P<0.05$. Results: Increased ANB, short mandibular length, negative value of facial axis, large value of MP angle, Y-axis, and LAFH. There was also a significant correlation between mandibular length and various variables, namely, facial axis, ANB angle, and LAFH. Conclusions: Skeletal Class II malocclusion in South Rajasthan population at Daswani Dental College and Research Center was characterized by short mandibular length and large ANB mostly not by the increased of SNA but by the lack of SNB. The length of mandible correlated with facial axis angle, lower anterior facial height, and mandibular plane angle.

\section{INTRODUCTION}

Class II malocclusion is characterized by a skeletal difference of the maxillary bases vs the bases of the skull, produced through maxillary protrusion and/or mandibular retrusion with ANB angle $\geq 4^{\circ}$.According to angle a class II malocclusion is a more than one half the width of one cusp distal relation of the lower to the upper first permanent molar. According to the Angle's classification there are two clinical forms: division 1, with proclination of the upper incisors and increased overjet; division 2, with retroclination of the upper incisors and minimum overjet. ${ }^{1}$ Skeletal class II pattern may arise from horizontal as well as vertical discrepancies. The most difficult thing in skeletal class II patients is to control vertical dimension therefore, it is very crucial to thoroughly understand the vertical face height (VFH) in orthodontic treatment which includes AFH and PFH. Some reports indicated that skeletal class II is because of protrusive maxilla and normal mandible other study found that the maxilla was normal while the mandible was retrusive. Other found that it is because of both maxillary prognathism and mandibular retrognathism. It seems that the ethnic backgrounds of samples used in these studies have played a role in determining the craniofacial characterstics of the class II pattern. ${ }^{2}$

\section{MATERIALS AND METHODS}

The research consists of 100 lateral cephalometric X-rays of south Rajasthan adult population who were seeking orthodontic treatment at Daswani Dental College and Research Center. Inclusion criteria of samples selection include, ANB $\geq 4^{\circ}$, and complete permanent dentition. Exclusion criteria of samples selection consists of, genetic syndrome, a history of orthodontic treatment, dentofacial trauma or temporomandibular joint disorders, supernumerary teeth and missing teeth. From 171 patients, 100 samples were found eligible based on above criteria with age range of 16 to 35 years of which 50 were male and 50 were female. A total of 100 lateral cephalograms of pre orthodontic patients with age ranging from 16 to 35 years with skeletal Class II malocclusion i.e, $\geq 4^{\circ}$, were obtained from Daswani Dental College and Research Center. The lateral cephalograms were taken using digital cephalometric machine (planmica) and were 
analysed by manual tracing with experienced post graduates to determine the ANB, mandibular length, facial axis, Y-axis, sella to nasion-mandibular plane (SN-MP), lower anterior facial height (LAFH), FMA, gonial angle, saddle angle and articulare angle. For each patient a lateral cephalogram was then taken in natural head position while patient kept their teeth in centric occlusion and lips in relaxed position. Cephalometric analysis performed using planmica digital cephalometric by a single examiner.

Reference lines and landmark to be analyzed:

1. ANB: Angle between SNA and SNB 2. Mandibular length: A line measured from the Condyle (Co) to the anatomic Gnathion (Gn) 3. SN-MP: Angle between SN and GoGn 4. Facial axis: Angle between basion to nasion and posteriosuperior aspect of pterygomaxillary fissure to constructed gnathion 5. Y-axis: Angle between Frankfort horizontal and sella to gnathion 6. LAFH: A line measured from the anterior nasal spine to the menton 7.FMA- formed by the intersection of the Frankfort horizontal plane (po- or) and the mandibular plane (go-me) 8. Gonial angle - the angle formed by the intersection of a line tangent to the posterior border of the ramus and the mandibular plane. It indicates the mandibular growth direction. 9. Saddle angle angle formed by joining points Nasion - Sella - Articulare. it increases when the condyle and mandible are posteriorly positioned w.r.t cranial base and maxilla. 10. Articulare angle - angle formed by joining the points sella-Ar-Go, which is the constructed angle between the upper and lower contours of the facial skeleton.

\section{Statistical analysis}

The mean and standard deviation for cephalometric measurement obtained were calculated using SPSS version 17.0 (IBM Company, New York, USA) while the data distribution was analyzed using Kolmolgorov-Smirnov- $Z$ and Pearson correlation test was used to determine the possible correlation between mandibular length and other variables.

\section{RESULTS}

The mean and standard deviation value for cephalometric analysis measurement are - 


\begin{tabular}{|c|c|}
\hline Measurement & Mean \pm SD \\
\hline SNA $\left(^{\circ}\right)$ & $82.34 \pm 3.87$ \\
\hline $\mathrm{SNB}\left(^{\circ}\right)$ & $76.04 \pm 3.79$ \\
\hline$A N B\left({ }^{\circ}\right)$ & $6.30 \pm 1.57$ \\
\hline Mandibular length(mm)[co-gn] & $111.66 \pm 7.83$ \\
\hline Facial axis $\left({ }^{\circ}\right)$ & $87.69 \pm 6.28$ \\
\hline$Y-\operatorname{Axis}\left({ }^{\circ}\right)$ & $62.41 \pm 4.65$ \\
\hline SN-MP(o) [SNGoGn] & $30.19 \pm 8.64$ \\
\hline $\mathrm{LAFH}(\mathrm{mm})$ & $67.63 \pm 5.90$ \\
\hline FMA $\left(^{\circ}\right)$ & $26.33 \pm 7.76$ \\
\hline Gonial Angle( $\left.{ }^{\circ}\right)$ & $133.88 \pm 99.67$ \\
\hline Saddle Angle( $\left.{ }^{\circ}\right)$ & $124.13 \pm 5.171$ \\
\hline Articulare Angle( $\left.{ }^{\circ}\right)$ & $144.74 \pm 6.47$ \\
\hline
\end{tabular}

Pearson correlation test showed that there is a significant correlation between mandibular length and other variables, such as ANB $(r=-.320 ; p$ value $=0.001)$, Facial axis $(r=0.245 ; p$ value $=$ $0.014)$ and LAFH $(r=0.475 ; p$ value $=0.000)$. However, there is no significant correlation between mandibular length and $\mathrm{Y}$-axis $(\mathrm{r}=-0.044 ; \mathrm{p}$ value $=0.666)$, SNG0Gn $(\mathrm{r}=-0.077 ; \mathrm{p}$ value $=0.446)$, FMA $(r=-0.050 ; p$ value $=0.621)$, Gonial Angle $(r=-0.042 ; p$ value $=0.680)$, Saddle Angle $(r=-0.033 ; p$ value $=0.748)$, Articulare Angle $(r=-0.008 ; p$ value $=0.939)$.

Correlation between Mandibular length(co-gn) and ANB, Facial axis, Y-Axis, SNGoGn, LAFH, FMA, Gonial Angle, Saddle Angle, Articulare Angle.

\begin{tabular}{|l|l|l|l|l|l|l|l|l|l|l|}
\hline & & ANB & $\begin{array}{l}\text { Facial } \\
\text { axis }\end{array}$ & Y-Axis & $\begin{array}{l}\text { SN } \\
\text { Go } \\
\text { Gn }\end{array}$ & LAFH & FMA & $\begin{array}{l}\text { Gonial } \\
\text { Angle }\end{array}$ & $\begin{array}{l}\text { Saddle } \\
\text { Angle }\end{array}$ & $\begin{array}{l}\text { Articulare } \\
\text { Angle }\end{array}$ \\
\hline $\begin{array}{l}\text { co- } \\
\text { gn }\end{array}$ & $\begin{array}{l}\text { Pearson } \\
\text { correlation(r) }\end{array}$ & -.320 & 0.245 & -0.044 & -.077 & 0.475 & -0.050 & -0.042 & -0.033 & -0.008 \\
\cline { 2 - 10 } & p value & 0.001 & 0.014 & 0.666 & 0.446 & 0.000 & 0.621 & 0.680 & 0.748 & 0.939 \\
\hline $\mathrm{n}$ & 100 & & & & & & & & & \\
\hline
\end{tabular}

Since the $\mathbf{p}$ value is less than $\mathbf{0 . 0 5}(95 \% \mathrm{CI})$, we reject the null hypothesis saying that there is significant correlation between mandibular length(co-gn) and the variables ANB ( $\mathrm{r}=-.320 ; \mathrm{p}$ value $=0.001)$, Facial axis $(r=0.245 ; \mathrm{p}$ value $=0.014)$ and LAFH $(\mathrm{r}=0.475 ; \mathrm{p}$ value $=0.000)$. Since the $\mathbf{p}$ value is greater than $\mathbf{0 . 0 5}(95 \% \mathrm{CI})$, we fail to reject the null hypothesis saying that there is no significant correlation between mandibular length(co-gn) and the variables Y-axis, SNG0Gn, FMA, Gonial Angle, Saddle Angle, Articulare Angle.

GRAPHS: Pearson Correlation between Mandibular length(co-gn) and the variables ANB, Facial axis, LAFH. The graph represents the Pearson correlation value(r) between mandibular length(co-gn) and the variables ANB, Facial axis, LAFH. 


\section{Mandibular length(co-gn) vs ANB,Facial axis, LAFH}

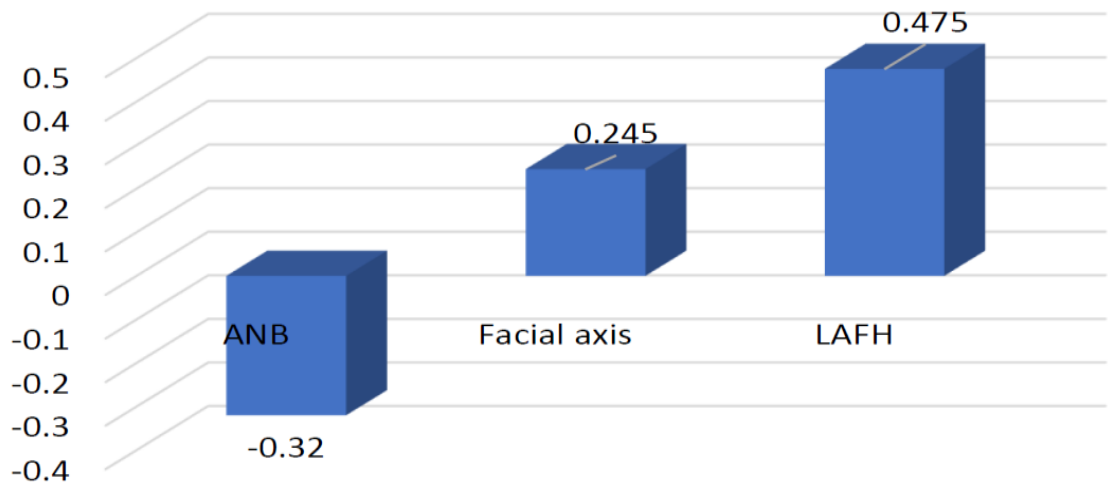

\section{DISCUSSION}

The measurement of mandibular length using GoGn as reference had been approved for long time as it is reliable and has a high consistency value. The results this study showed the mean value if mandibular length on skeletal Class II malocclusion was $111.66 \pm 7.83$.

\begin{tabular}{lcccccccc}
\hline \multicolumn{7}{c}{ Table 2: Cephalometric characteristic of skeletal Class II malocclusion in different ethnic } \\
\hline Ethnic & SNA & SNB & ANB & SNGoGn & Y-axis & Facial axis & LAFH & CoGn \\
\hline French Canadian $^{[14]}$ & $80.51 \pm 3.44$ & $76.09 \pm 3.16$ & $4.43 \pm 1.81$ & $35.54 \pm 5.29$ & - & - & - & $105.80 \pm 5.69$ \\
China $^{[7]}$ & $80.88 \pm 3.25$ & $74.71 \pm 3.29$ & $6.16 \pm 2.18$ & $35.88 \pm 6.65$ & $66.96 \pm 4.42$ & - & - & - \\
Nepal $^{[7]}$ & $81.22 \pm 4.30$ & $76.52 \pm 4.00$ & $4.75 \pm 2.95$ & $29.13 \pm 8.21$ & $61.37 \pm 5.21$ & - & - & - \\
Saudi $^{[15]}$ & $81.32 \pm 3.12$ & $75.25 \pm 2.99$ & $6.00 \pm 2.33$ & $36.35 \pm 3.71$ & $70.00 \pm 3.09$ & - & $54.54 \pm 3.04$ & - \\
Italy $^{[16]}$ & $80.4 \pm 2.2$ & $73.5 \pm 1.6$ & $6.8 \pm 1.7$ & $37.5 \pm 3.3$ & - & - & - & $94.5 \pm 3.1$ \\
Iraqi $^{[17]}$ & $87.3 \pm 2.00$ & - & - & $34.59 \pm 3.49$ & - & $-0.60 \pm 0.169$ & $63.63 \pm 2.96$ & $102.30 \pm 3.25$ \\
\hline
\end{tabular}

These results agree with the previous study which stated that Class II have smallest mean of mandibular length compare to Class I and III. Kerr and Hirst showed a significant difference of mandible length on normal group compared to Class II malocclusion. ${ }^{3}$

Class II patient had a convex profile with a disto-occlusion pattern; the mandible is significantly more retruded than in Class I patients with the body of mandible smaller and overall mandibular length shorter. Trend of skeletal Class II malocclusion pattern in south Rajasthan population examined in this study has a convex facial profile as $>80 \%$ of patients has a similarity in craniofacial growth pattern, which was the deficiency of mandibular length termed as mandibular micrognathia. ${ }^{3}$

McNamara ${ }^{4}$ mentioned that excessive vertical development is indicated by negative values $\left(<90^{\circ}\right)$ while deficient vertical facial development is indicated by positive values $\left(>90^{\circ}\right)$, which is obtained by measuring the angle formed of basion-PTM-gnathion and expected to have perpendicular relationship in a balanced face. The mean value of facial axis found in this study was $87.69 \pm 6.28$. According to previous studies which state that the facial axis angle in Class III 
females have the greatest degree, whereas Class II males and females have the smallest degree. In this study Y-axis and SN-MP have bigger value than normal range, while the LAFH is above normal range. The respective values were also found greater compared to other ethnic with Class II malocclussion as presented in the table which shows the variation of facial pattern in skeletal Class II, which was affected by different ethnic background. It reveals to us the important role of genetic influence on each malocclusion type. As the prior study stated that there will be significant different cephalometric value between two different ethnic backgrounds. ${ }^{5}$

. Pearson correlation coefficients were used in this study, to find out the interrelationship among variable measurement. There was significant correlation within the mandibular length and other variables, such as facial axis. Smaller the mandibular length, more negative value of the facial axis angle, as a compensation of facial growth and development. This excessive vertical development will cause mandible to seem retruded and long face profile.

During the process of mandiblular growth, the length of the long bone increase in a rectilinear direction along its long axis, then condylar process grows in a wide range of direction from anterosuperior to posterior. This highly diverse growth and morphology of mandible is provided by above divergent growth. ${ }^{6}$

The displacement direction of the mandible (transposition) and vertical jaw deviation is related to the condylar growth.

Negative facial axis is due to an increase of mandibular angle which is characterized by posterosuperior condylar growth, apposition of inferior gonial, and inferoposterior mandible displacement. On the other hand, small mandibular angle was characterized by anterosuperior condyle growth, absorption of inferior gonial and anterior mandible displacement. ${ }^{7}$

There was significant correlation between mandibular length and ANB. The bigger mandibular length will cause smaller ANB, vice versa.

There was also significant correlation between mandibular length and SN-MP. The shorter mandibular length, the bigger MP angle. Mean value of SN-MP was 30.19. $\pm 8.64^{\circ}$. According to Jacobson, ${ }^{8}$ the normal value of mandibular angle is $32^{\circ}$ and any more or less value will show unfavorable growth pattern and hence will affect the treatment results. SN-MP describes the relation between mandible base to cranium. Large angle shows domination of vertical growth while small angle shows horizontal growth. ${ }^{9}$

While the mean value of $\mathrm{Y}$-axis was $62.41 \pm 4.65^{\circ}$ with no significant correlation to mandibular length. Facial pattern on Class II malocclusion has larger Y-axis compared to Class I and III. Increasing $\mathrm{Y}$-axis shows vertical growth of the mandible. Standard value of Y-axis in normal condition was range between 53 and 66 .

LAFH mean value is $67.63 \pm 5.90 \mathrm{~mm}$ with significant correlation to mandibular length. Ali described that LAFH (ANS-Me) had the greatest values in males of Class II group, this was in 
line with McNamara who stated that an increase in LAFH will make the mandible to appear more retrognathic while if this height is decreased, the mandible will appear to be more prognathic. There is an increase of LAFH in hyperdivergent patients, while hypodivergent patients have a shorter LAFH. The previous studies stated that the increase of LAFH was caused by the backward rotation of mandible, where maxilla also descends down to compensate the mandibular growth. And the results of this study are also in accordance with the same. Opdebeeck and Bell ${ }^{10}$ stated that long face syndrome was attributed to clockwise rotation of mandible and short face syndrome attributed to counterclockwise rotation of mandible.

As stated by Björk and Skieller, forward mandibular rotation occurs when posterior facial height $(\mathrm{PFH})$ overdevelops in relation to anterior facial height $(\mathrm{AFH})$. However, many literatures were more focused on the AFH and LAFH values as it has been confirmed to have a great influence on the development of vertical facial disproportions. A high or low mandibular plane angle might not necessarily be accompanied by short or long anterior face height, respectively. Rather than AFH, PFH is assumed to play a key role in vertical facial type, while AFH seems to undergo relatively intrinsic growth. The reason for mandibular forward rotation is not caused by the combination of an increase in $\mathrm{PFH}$ and decrease in $\mathrm{AFH}$, but due to their different dimension increase. Van Spronsen et al. ${ }^{11}$ proposed that musculoskeletal interaction might be different in between populations with normal faces and selected group of individuals with long faces.

FMA mean value is $26.33 \pm 7.76 \mathrm{~mm}$ with no significant correlation to mandibular length. In a study done on young adults by shail kumari Mishra and sunil kumar Mishra the mean values of FMA are

\begin{tabular}{|l|l|c|c|c|c|c|c|}
\hline \multirow{2}{*}{$\begin{array}{l}\text { Ser } \\
\text { No. }\end{array}$} & \multirow{2}{*}{ FMA(degrees) } & \multicolumn{2}{|c|}{$\begin{array}{c}\text { Young Children } \\
\text { Males } \\
\text { (b) }\end{array}$} & \multicolumn{2}{c|}{$\begin{array}{c}\text { Young Children } \\
\text { Females } \\
\text { (c) }\end{array}$} & \multirow{2}{*}{ t-value } & p-value \\
\cline { 3 - 7 } & & Mean & S.D & Mean & & \\
\hline $\mathbf{1}$ & FMA Class I & 26.27 & 4.06 & 25.33 & 6.27 & 0.4874 & 0.6298 \\
\hline $\mathbf{2}$ & $\begin{array}{l}\text { FMA Class II } \\
\text { Div 1 }\end{array}$ & 25.73 & 5.48 & 27.87 & 5.72 & 1.046 & 0.3044 \\
\hline $\mathbf{4}$ & $\begin{array}{l}\text { FMA Class II } \\
\text { Div 2 }\end{array}$ & 22.60 & 5.15 & 24.07 & 5.13 & 0.7832 & 0.4401 \\
\hline
\end{tabular}

The FMA angle of skeletal class II patients in this study is within the normal range . In inter class comparison FMA was significantly high in Class II div 1(25.63) when compared to Class II div 2(24.77). FMA was also significantly high in Class II div 1(25.63) when compared to Class III (21.50). This may be attributed to more forward growth tendency of mandible in class III subjects compare to class II div1 and div 2, which result in prognathic mandible in class III subjects and retrognathic mandible in class II div 1 subjects. ${ }^{12}$

Gonial angle mean value is $133.88 \pm 9.67 \mathrm{~mm}$ with no significant correlation to mandibular length. Gonial angle size appears to be inversely related to and significantly correlated with mandibular body length and the size of angles SNA and ANB. ${ }^{13}$ An Increased gonial angle is 
accompanied by an increased mandibular length. Björk described an increase in curvature of the mandibular base and noted that this increase was accompanied with a reduction in size of the gonial angle. This reduction, successively, was accompanied by vertical condylar growth, whereas both the gonial angle and sagittal growth were increased. ${ }^{14}$

Mandibular length was not entirely related to gonial angle size. The mandibular body length was significantly related and inversely proportional to the gonial angle size. That is, individuals with a small gonial angle tended to have a larger mandibular body length and the SNA angle and ANB angle were also larger in cases with a smaller gonial angle.

Saddle angle has no relation with mandibular size according to this study. according to a study done by Yassir A. Yassir an increase in saddle angle is associated with true mandibular size deficiency. Järvinen stated that a large N-S-Ar angle is associated with facial retrognathism, a small N-S-Ar angle with facial prognathism. ${ }^{15}$

\section{CONCLUSIONS}

Skeletal Class II Malocclusion with mandibular micrognathia in south Rajasthan population at Daswani Dental College and Research Center was characterized by an increased ANB, short mandibular length, negative value of facial axis, large value of MP angle, Y-axis, and LAFH. There was also a significant correlation between mandibular length and various variables, namely, facial axis, ANB angle, and LAFH.

\section{REFERENCES}

1. Zegan G, Dascalu CG, Mavru RB, Anistoroaei D. Cephalometric features of class III malocclusion. The Medical-Surgical Journal. 2015 Dec 31;119(4):1153-60.

2. Ardani IG, Willyanti I, Narmada IB. Correlation between vertical components and skeletal Class II malocclusion in ethnic Javanese. Clinical, cosmetic and investigational dentistry. 2018;10:297.

3. Ardani IG, Sanjaya ML, Sjamsudin J. Cephalometric characteristic of skeletal class II malocclusion in Javanese population at Universitas Airlangga Dental Hospital. Contemporary clinical dentistry. 2018 Sep;9(Suppl 2):S342.

4. McNamara JA Jr. A method of cephalometric evaluation. Am J Orthod 1984;86:449-69

5. Wu J, Hägg U, Rabie AB. Chinese norms of McNamara's cephalometric analysis. Angle Orthod 2007;77:12-20

6. Björk A, Skieller V. Normal and abnormal growth of the mandible. A synthesis of longitudinal cephalometric implant studies over a period of 25 years. Eur J Orthod $1983 ; 5: 1-46$ 
7. Mizoguchi I, Noko T, Yuya N. Growth of the mandible and biological characteristics of the mandibular condylar cartilage. Jpn Dent Sci Rev 2013;49:139-50.

8. Jacobson A. Radiographic Cephalometry: From Basics to Videoimaging. London: Quintessence Publishing Co.; 1995.

9. Scanavini C, Vigoriro JW. Cephalomerric-radiographic study of the possible correlations existence between Vigori, Rickett, Siriwat and Jarabak analysis on facial patterns determination. Ortodontia 2001;34:27-41

10. Opdebeeck H, Bell WH, Eisenfeld J, Mishelevich D. Comparative study between the SFS and LFS rotation as a possible morphogenic mechanism. Am J Orthod 1978;74:509-21

11. van Spronsen PH, Koolstra JH, van Ginkel FC, Weijs WA, Valk J, Prahl-Andersen B, et al. Relationships between the orientation and moment arms of the human jaw muscles and normal craniofacial morphology. Eur J Orthod 1997;19:313-28

12. Kumari S, Mishra SK, Chouksey G, Prakash A, Kumar A. EVALUATION OF FRANKFORT-MANDIBULAR PLANE ANGLE IN DIFFERENT MALOCCLUSION OF CENTRAL INDIA. Journal of Oral and Dental Health| Vol. 2019;5(1):69.

13. de Rossi M, Stuani MBS, da SLAB. Cephalometric evaluation of vertical and anteroposterior changes associated with the use of bonded rapid maxillary expansion appliance

14. Kim YH. Overbite depth indicator with particular reference to anterior open-bite. Am J Orthod. 1974;65(6):586-611.

15. Yassir YA. Saddle angle and its relationship with maxillary and mandibular lengths. Iraqi Orthod J. 2009;5(1):14-6. 